\title{
Analisa Pengaruh Material Abrasif Pada Blasting Terhadap Kekuatan Lekat Cat dan Ketahanan Korosi di Lingkungan Air Laut
}

\author{
Carolus Trijatmiko ${ }^{1}$, Herman Pratikno ${ }^{1}$, dan Agung Purniawan ${ }^{2}$ \\ ${ }^{1}$ Jurusan Teknik Kelautan, Fakultas Teknik Kelautan, Institut Teknologi Sepuluh Nopember (ITS) \\ ${ }^{2} J u r u s a n$ Teknik Material dan Metalurgi, Fakultas Teknologi Industri, Institut Teknologi Sepuluh Nopember (ITS) \\ Jl. Arief Rahman Hakim, Surabaya 60111 Indonesia \\ e-mail: hermanp@oe.its.ac.id
}

\begin{abstract}
Abstrak-Coating merupakan proses pelapisan pada permukaan profil material dengan suatu lapisan film organik maupun anorganik. Coating lebih sering digunakan pada industry karena lebih ekonomis dan lebih mudah digunakan. Namun teknik ini pun tidak lepas dari berbagai masalah. Masalah yang timbul dari teknik ini sebagian besar disebabkan karena buruknya proses surface preparation yang dapat mengurangi daya lekat cat. Buruknya proses surface preparation dapat disebabkan berbagai hal antara lain ukuran mesh dari material abrasif yang tidak pas, pemilihan material abrasif, hingga kesalahan teknik dalam melakukan proses ini. Penelitian ini dilakukan untuk menganalisa pengaruh dari material abrasif terhadap kekuatan lekat cat di material A36 yang diberikan variasi jenis material abrasif alumunium oxide, steel grit, dan volcanic sand, kemudian material di coating dengan cat jenis epoxy dan zinc rich. Hasil dari pengujian menunjukan bahwa peningkatan kekerasan material abrasif meningkatkan kekasaran permukaan pada substrat. Nilai rata-rata kekasaran permukaan yang tertinggi adalah material yang di blasting dengan steel grit yaitu sebesar $84.71 \mu \mathrm{m}$. Meningkatnya kekasaran permukaan akan menambah daya lekat cat dengan substrat, yang juga akan meningkatkan ketahanan korosi pada material. Nilai daya lekat tertinggi pada material yang di coating dengan cat jenis epoxy dan zinc rich berturut-turut sebesar 20.04 MPa dan $21.46 \mathrm{MPa}$, dimana material tersebut di blasting dengan menggunakan steel grit. Hasil dari pengujian salt spray NaCl $3.5 \%$ selama 72 jam, dan 168 jam pada material menunjukan material yang di blasting dengan steel grit tetap memiliki nilai daya lekat yang tertinggi. Nilai daya lekat tertinggi setelah uji salt spray selama 72 jam pada material yang di coating dengan cat jenis epoxy dan zinc rich berturut-turut sebesar 14.15 MPa dan 15.04 MPa, sedangkan Nilai daya lekat tertinggi setelah uji salt spray selama 168 jam pada material yang di coating dengan cat jenis epoxy dan zinc rich berturutturut sebesar 11.91 MPa dan 12.80 MPa.
\end{abstract}

Kata Kunci-Coating, Blasting, Material Abrasif, Steel Grit, Salt Spray.

\section{PENDAHULUAN}

$\mathrm{D}$ ALAM industri maritim, logam merupakan bahan dasar dalam pembuatan kapal dan bangunan lepas pantai. Logam sendiri adalah unsur kimia yang mempunyai sifat-sifat kuat, keras, penghantar listrik dan panas, serta mempunyai titik cair tinggi. Namun logam memiliki kekurangan yaitu mudah mengalami korosi. Korosi merupakan salah satu faktor pertimbangan dalam industri maritim dan industri minyak dan gas. Dampak-dampak lain dari korosi antara lain kerusakan struktur, kerusakan alat-alat produksi, dan berkurangnya umur struktur. Proses terjadinya korosi tidak dapat dihentikan namun hanya bisa dikendalikan atau diperlambat lajunya. Dalam industri maritim laju korosi sangat cepat karena lingkungan laut sangat korosif.

Seiring dengan berkembangnya teknologi ditemukan pula beberapa cara untuk memperlambat laju korosi, salah satunya adalah dengan proses pelapisan (coating). Pelapisan (coating) adalah proses untuk melapisi suatu bahan dasar (substrate) yang bertujuan untuk melindungi material dari korosi dan memberi perlindungan pada material tersebut. Selain itu, coating juga memberikan gaya apung negatif (negative buoyancy force), memberikan fungsi anti-slip pada permukaan substrat dan beberapa fungsi lainnya [1].

Keberhasilan dari proses coating sangat tergantung pada proses surface preparation, dimana proses ini akan mempengaruhi kekuatan adhesi dari material [2]. Salah satu teknik dari surface preparation yang umum digunakan dalam dunia industri adalah blasting. Proses ini merupakan pembersihan permukaan dengan cara menembakan material abrasif ke suatu permukaan material dengan tekanan tinggi sehingga menimbulkan gesekan/ tumbukan. Permukaan material tersebut akan menjadi bersih dan kasar. Pemilihan dan penggunaan material abrasif yang tepat akan menambah daya lekat cat. Oleh karena itu, pada penelitian ini akan dipelajari tentang analisa pengaruh material abrasif pada blasting terhadap kekuatan lekat cat di lingkungan laut.

\section{METODE PENELITIAN}

\section{A. Preparasi Substrat dan Sampel}

Pada penelitian ini spesimen yang digunakan adalah baja karbon ASTM A36 dengan ketebalan $1 \mathrm{~cm}$ yang dipotong menjadi dimensi 10x10 cm sebanyak 54 buah yang akan digunakan sebagai spesimen uji daya adhesi dan untuk uji salt spray, serta dimensi 2x1,5 cm sebanyak 18 buah untuk pengujian laju korosi. Dilakukan proses pembersihan permukaan menggunakan blasting dengan variasi material abrasif dengan jenis alumunium oxide, steel grit, volcanic sand. Material cat yang digunakan pada penelitian ini adalah 
cat primer epoksi dan cat primer zinc rich.

Proses pengaplikasian cat pada permukaan substrat dilakukan menggunakan conventional air spray. Pengecatan dilakukan pada temperatur kamar. Setelah itu, spesimen yang telah dicat dikeringkan (curing) pada temperatur kamar selama 7 hari.

\section{B. Metode Pengujian}

Pengujian daya lekat dilakukan sesuai dengan standar ASTM D-4541 [3]. Untuk mengetahui besar daya lekat cat masing - masing variabel pada permukaan spesimen. Pengujian salt spray dengan $\mathrm{NaCl} 5 \%$ digunakan untuk mempercepat laju korosi dan juga untuk melihat ketahanan cat akibat lingkungan yang korosif selama 72 jam dan 168 jam. Pengujian ini dilakukan sesuai dengan standar ASTM B-117 [4]. Setelah dilakukan pengujian salt spray, kembali dilakukan pengujian daya lekat untuk melihat penurunan kekuatan lekat cat pada spesimen.

Pengujian laju korosi dilakukan dengan metode sel 3 elektroda yang terhubung dengan alat potensiostat Autolab PGSTAT128N, dan software NOVA.

\section{HASIL DAN PEMBAHASAN}

\section{A. Pengujian Kekasaran Permukaan}

Pengujian ini dilakukan setelah proses blasting sesuai dengan standar ASTM D-4417 [5]. Dengan tujuan untuk mengukur kekasaran permukaan spesimen setelah dilakukan proses blasting dengan material abrasif (alumunium oxide, steel grit, volcanic sand) dengan mesh size 16 dan tekanan sebesar 5 bar.

Berdasarkan gambar 1 didapatkan nilai rata-rata kekasaran permukaan pada material yang di blasting menggunakan material abrasif jenis volcanic sand sebesar $62.61 \mu \mathrm{m}$, untuk material yang di blasting menggunakan material abrasif jenis alumunium oxide sebesar $78.61 \mu \mathrm{m}$, dan material yang di blasting menggunakan material abrasif jenis steel sebesar $84.71 \mu \mathrm{m}$.

Nilai rata-rata kekasaran permukaan dari material yang di blasting menggunakan material abrasif steel grit memiliki nilai rata-rata yang paling tinggi, kemudian diikuti oleh material yang di blasting menggunakan material abrasif alumunium oxide, lalu yang memiliki nilai rata-rata kekasaran permukaan paling kecil adalah material yang di blasting menggunakan material abrasif volcanic sand. Material yang di blasting menggunkan material abrasif steel grit memiliki nilai rata-rata kekasaran permukaan paling tinggi diantara material lain dikarenakan nilai kekerasan material abrasif steel grit paling tinggi yaitu 8-9 MOHS, lalu diikuti oleh material abrasif alumunium oxide yang memiliki nilai kekerasan sebesar 7 MOHS, dan yang terakhir adalah material abrasif volcanic sand yang memiliki nilai kekerasan 5.5-6.5 MOHS.

Dengan kata lain semakin tinggi nilai kekerasan partikel suatu material abrasif yang digunakan untuk proses blasting, maka akan semakin besar pula nilai kekasaran permukaan suatu material. Hal ini disebabkan karena dengan nilai kekerasan material abrasif yang semakin tinggi, maka energi yang dimiliki material abrasif juga semakin tinggi, sehingga ketika partikel ditembakkan terjadi tumbukkan dengan permukaan substrat dan terjadi deformasi yang semakin besar.

\section{B. Pengamatan Visual Hasil Blasting}

Inspeksi visual hasil blasting dilakukan untuk memastikan bahwa material yang telah di blasting sesuai dengan tingkat kebersihan yang ingin dicapai yaitu SA 3 (ISO 8501-1) [6]. Adapun cara untuk melakukan pengujian ini adalah membandingkan material yang telah di blasting dengan standard visual yang tertera pada SSPC-VIS 1 - Guide and Reference Photographs for Steel Surfaces Prepared by Dry Abrasive Blast Cleaning [7]. Hasil inspeksi visual dapat dilihat pada gambar 2 .

Dari hasil inspeksi visual dapat dilihat bahwa seluruh material yang di blasting menggunakan alumunium oxide, steel grit, dan volcanic sand telah mencapai tingkat kebersihan SA 3 (ISO 8501-1). Ciri-ciri suatu material telah mencapai tingkat kebersihan SA 3 atau white metal adalah material meiiliki permukaan yang bersih dari minyak, grease, debu, mill scale, karat, dan bekas cat lama, dan juga dalam tingkat kebersihan SA 3 ini, material akan memunculkan warna aslinya.

\section{Pengujian Daya Lekat}

Pengujian daya lekat dilakukan untuk mengukur kekuatan daya lekat cat dengan antara lapisan cat dengan substrat. Standart yang digunakan untuk pengujian ini adalah ASTM D4541-02. Standar NORSOK M-501[8] memberikan nilai kekuatan adhesi minimum yaitu $5 \mathrm{MPa}$.

Pada Gambar 2 terlihat bahwa spesimen yang di blasting menggunakan material abrasif steel grit memiliki nilai daya lekat yang paling tinggi baik spesimen yang di coating menggunakan cat primer epoxy maupun spesimen yang di coating menggunakan cat primer zinc rich. Hal ini terjadi karena permukaan spesimen yang di blasting menggunakan material abrasif steel grit, memiliki struktur permukaan yang lebih kasar dibandingkan dengan spesimen yang di blasting menggunakan material abrasif alumunium oxide, maupun spesimen yang di blasting menggunakan material abrasif volcanic sand. Semakin kasar suatu permukaan material akan menambah area kontak antara cat dan substrat, sehingga akan menambah kekuatan lekat cat, ketika permukaan lebih halus maka cat akan kehilangan mechanical interlocking dengan substrat yang akan mengurangi kekuatan lekat nya [9].

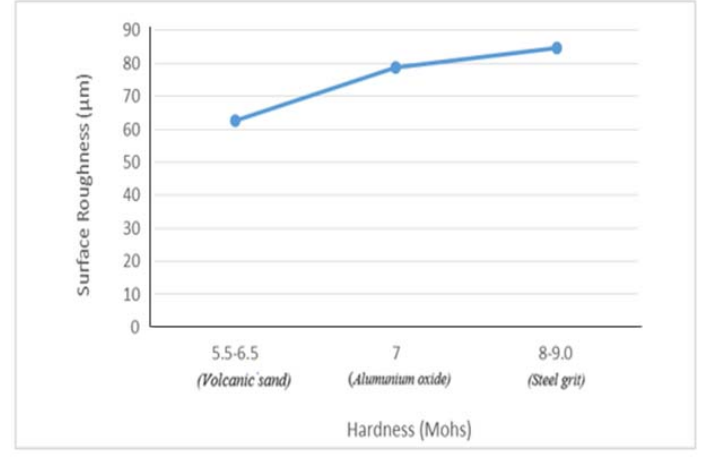


Gambar 1. Grafik Nilai Kekasaran Permukaan Berdasarkan Kekerasan Material Abrasif
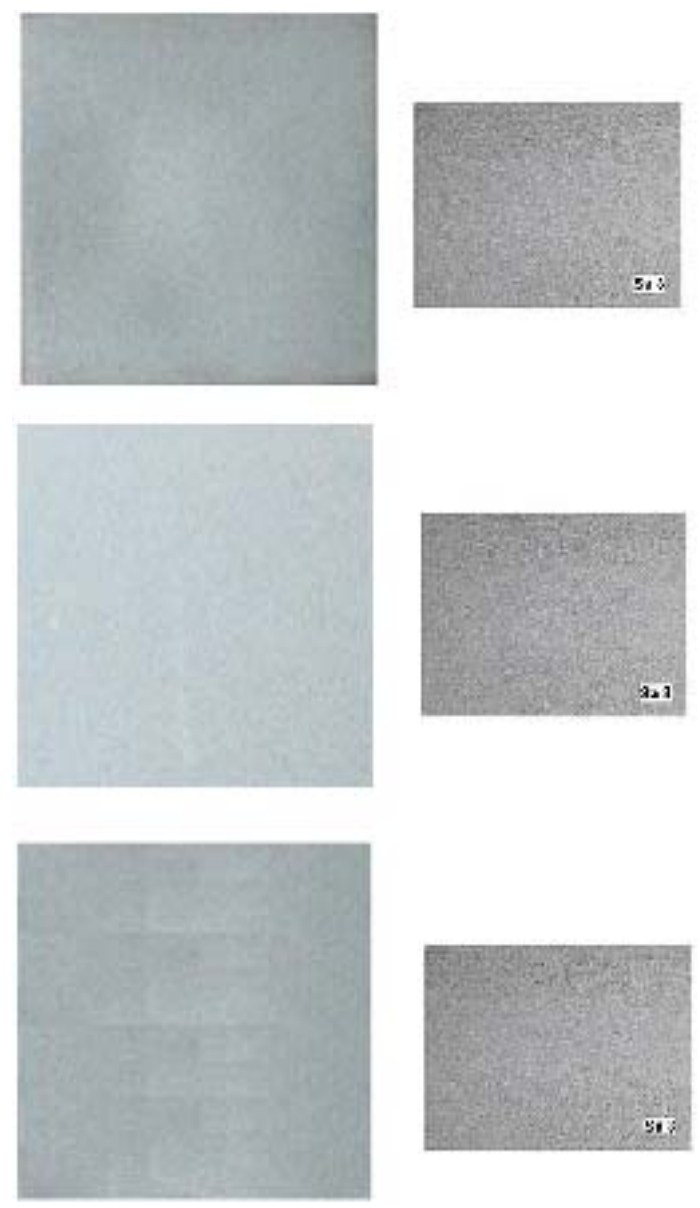

Gambar 2. Inspeksi visual hasil Blasting dengan (a) material abrasif Alumunium Oxide (b) material abrasif Steel Grit (c) material abrasif Volcanic Sand

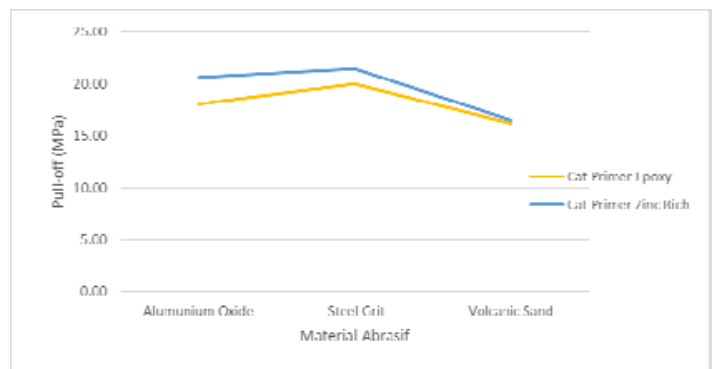

Gambar 3. Grafik Nilai Daya Lekat Cat Pada Permukaan Material

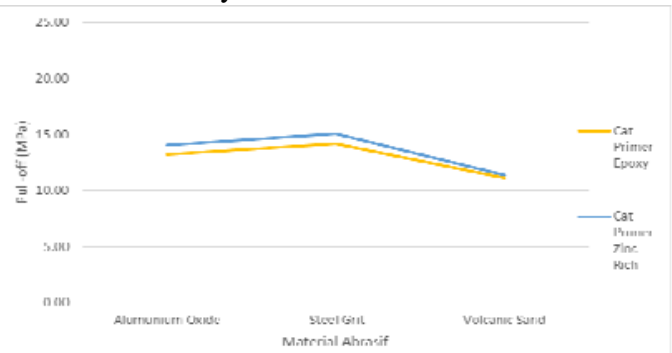

Gambar 2. Grafik Nilai Daya Lekat untuk spesimen setelah di salt spray 72 jam

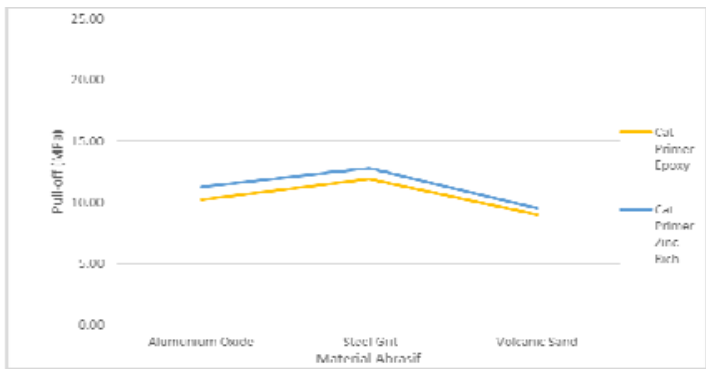

Gambar 5. Grafik Nilai Daya Lekat untuk spesimen setelah di salt spray 168 jam

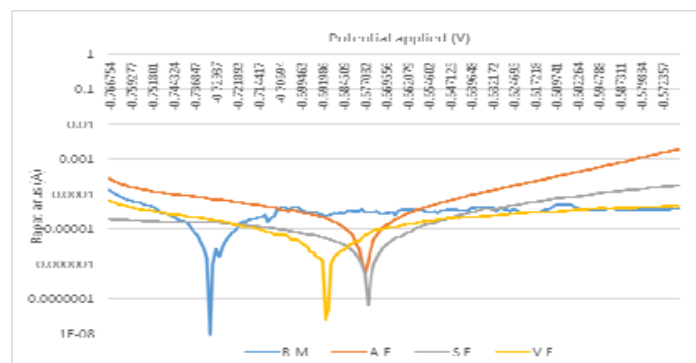

Gambar 6. Rata-rata diagram tafel material dengan cat primer epoxy Keterangan :

$\mathrm{R}-\mathrm{M}=$ Raw Material

A-E = Material yang di blasting menggunakan material abrasif alumunium oxide dan di coating dengan cat primer epoxy

$\mathrm{S}-\mathrm{E}=$ Material yang di blasting menggunakan material abrasif steel grit dan di coating dengan cat primer epoxy

$\mathrm{V}-\mathrm{E}=$ Material yang di blasting menggunakan material abrasif volcanic sand dan di coating dengan cat primer epoxy

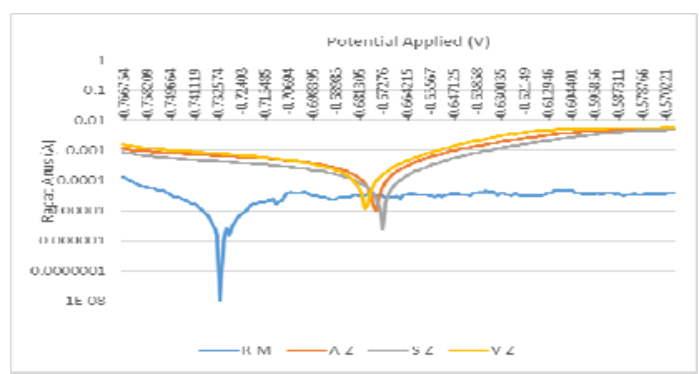

Gambar 7. Rata-rata diagram tafel material dengan cat primer epoxy Keterangan :

$\mathrm{A}-\mathrm{Z}=$ Material yang di blasting menggunakan material abrasif alumunium oxide dan di coating dengan cat primer zinc rich

$\mathrm{S}-\mathrm{Z}$ = Material yang di blasting menggunakan material abrasif steel grit dan di coating dengan cat primer zinc rich

$\mathrm{V}-\mathrm{Z}=$ Material yang di blasting menggunakan material abrasif volcanic sand dan di coating dengan cat primer zinc rich Tabel 1. Hasil Pengujian Pull-off Test

\begin{tabular}{|c|c|c|c|c|c|}
\hline \multirow{2}{*}{$\begin{array}{c}\text { Jenis Material } \\
\text { Abrasif }\end{array}$} & \multirow{2}{*}{ Jenis Cat } & \multicolumn{3}{|c|}{ Pull-off Test (MPa) } & \multirow{2}{*}{ Rata-rata (MPa) } \\
\cline { 3 - 5 } & & $\mathbf{1}$ & $\mathbf{2}$ & $\mathbf{3}$ & \\
\hline \multirow{2}{*}{ Alumunium Oxide } & Epoxy & 15.88 & 17.83 & 20.49 & 18.07 \\
\cline { 2 - 6 } & Zinc Rich & 21.68 & 20.15 & 20.10 & 20.64 \\
\hline \multirow{2}{*}{ Steel Grit } & Epoxy & 21.23 & 19.40 & 19.50 & 20.04 \\
\cline { 2 - 6 } & Zinc Rich & 22.53 & 20.48 & 21.38 & 21.46 \\
\hline \multirow{2}{*}{ Volcanic Sand } & Epoxy & 15.40 & 17.60 & 15.60 & 16.20 \\
\cline { 2 - 6 } & Zinc Rich & 16.20 & 15.08 & 18.20 & 16.49 \\
\hline
\end{tabular}

Tabel 2. Hasil Pengujian Daya Lekat Terhadap Spesimen dengan setelah di salt spray $72 \mathrm{jam}$ 


\begin{tabular}{|c|c|c|c|c|c|}
\hline \multirow{2}{*}{$\begin{array}{c}\text { Jenis Material } \\
\text { Abrasif }\end{array}$} & \multirow{2}{*}{ Jenis Cat } & \multicolumn{3}{|c|}{ Pull-off Test (MPa) } & \multirow{2}{*}{ Average (MPa) } \\
\cline { 3 - 5 } & & $\mathbf{1}$ & $\mathbf{2}$ & $\mathbf{3}$ & \\
\hline \multirow{2}{*}{ Alumunium Oxide } & Epoxy & 13.24 & 12.95 & 13.54 & 13.24 \\
\cline { 2 - 5 } & Zinc Rich & 13.99 & 13.26 & 14.84 & 14.03 \\
\hline \multirow{2}{*}{ Steel Grit } & Epoxy & 14.28 & 15.49 & 12.68 & 14.15 \\
\cline { 2 - 5 } & Zinc Rich & 14.02 & 16.44 & 14.67 & 15.04 \\
\hline \multirow{2}{*}{ Volcanic Sand } & Epoxy & 11.64 & 9.68 & 12.11 & 11.14 \\
\cline { 2 - 5 } & Zinc Rich & 11.27 & 10.40 & 12.40 & 11.36 \\
\hline
\end{tabular}

Tabel 3. Hasil Pengujian Daya Lekat Terhadap Spesimen dengan setelah di salt spray $168 \mathrm{jam}$

\begin{tabular}{|c|c|c|c|c|c|}
\hline \multirow{2}{*}{$\begin{array}{c}\text { Jenis Material } \\
\text { Abrasif }\end{array}$} & \multirow{2}{*}{ Jenis Cat } & \multicolumn{3}{|c|}{ Pull-off Test (MPa) } & \multirow{2}{*}{ Average (MPa) } \\
\cline { 2 - 5 } & & $\mathbf{1}$ & $\mathbf{2}$ & $\mathbf{3}$ & \\
\hline \multirow{2}{*}{ Alumunium Oxide } & Epoxy & 9.63 & 8.88 & 12.18 & 10.23 \\
\cline { 2 - 5 } & Zinc Rich & 10.76 & 12.58 & 10.50 & 11.28 \\
\hline \multirow{2}{*}{ Steel Grit } & Epoxy & 12.27 & 9.96 & 13.50 & 11.91 \\
\cline { 2 - 5 } & Zinc Rich & 14.06 & 11.66 & 12.67 & 12.80 \\
\hline \multirow{2}{*}{ Volcanic Sand } & Epoxy & 9.58 & 9.09 & 8.40 & 9.02 \\
\cline { 2 - 5 } & Zinc Rich & 9.14 & 9.84 & 9.65 & 9.54 \\
\hline
\end{tabular}

\section{Pengaruh Salt spray 5\% NaCl Terhadap Daya Lekat}

Pengujian Salt spray dilakukan sesuai dengan standar ASTM B-117 yang bertujuan untuk melihat ketahanan cat akibat lingkungan yang korosif. Pengujian salt spray dilakukan selama 72 jam dan 168 jam dengan kadar $\mathrm{NaCl}$ 5\%. Dari hasil pengujian salt spray didapatkan hasil yang ditunjukan pada tabel 2 dan grafik 3 untuk spesimen yang di salt spray selama 72 jam, sedangkan hasil untuk spesimen yang di salt spray selama 168 jam ditunjukan pada tabel 3 dan grafik 4.

Hasil dari pengujian salt spray selama 72 jam dan 168 jam menunjukan bahwa seluruh spesimen yang di blasting menggunakan material abrasif steel grit lalu di coating dengan cat primer epoxy dan cat primer zinc rich memiliki nilai daya lekat yang terbesar dibandingkan spesimen yang lainnya. Hal ini dikarenakan spesimen yang di blasting menggunakan material abrasif steel grit memiliki nilai rata-rata kekasaran permukaan yang lebih besar dibandingkan spesimen yang di blasting menggunakan material abrasif alumunium oxide, dan volcanic sand. Ketika nilai rata-rata kekerasan meningkat maka area kontak antara cat dengan substrat akan meningkat pula, hal ini akan menambah kekuatan lekat cat.

Terjadi penurunan nilai daya lekat pada setiap spesimen setelah dilakukan pengujian salt spray dikarenakan kehilangan dan/atau berkurangnya nilai daya lekat lapisan cat terhadap interface permukaan substrat disebabkan adanya kontaminan dan/atau korosi yang terjadi pada daerah interface tersebut [10].

\section{E. Pengujian Korosi}

Pengujian laju korosi dilakukan dengan metode sel 3 elektroda yang terhubung dengan alat potensiostat Autolab PGSTAT128N, dan software NOVA. Sampel yang digunakan untuk pengujian ini berukuran (20 mm x $15 \mathrm{~mm}$ x $10 \mathrm{~mm}$ ). Elektroda yang digunakan adalah elektroda acuan $\mathrm{Ag} / \mathrm{AgCl}$ dan elektroda pembantu platina. Software NOVA akan secara otomatis menunjukan laju korosi, potensial arus, nilai kerapatan, diagram tafel dari setiap spesimen. Rata-rata dari diagram tafel untuk material yang di cat dengan cat primer epoxy ditunjukan pada gambar 6 sedangkan rata-rata dari diagram tafel untuk material yang di cat dengan cat primer zinc rich ditunjukan pada gambar 7 .

Nilai laju korosi untuk material yang menggunakan material abrasif steel grit sebesar 0.0374 mmpy, untuk material yang menggunakan material abrasif alumunium oxide memiliki nilai laju korosi sebesar 0.0453 mmpy, sedangkan material yang menggunakan material abrasif alumunium oxide memiliki nilai laju korosi sebesar 0.0472 mmpy.

Nilai laju korosi untuk material yang menggunakan material abrasif steel grit sebesar 0.0353 mmpy, untuk material yang menggunakan material abrasif alumunium oxide memiliki nilai laju korosi sebesar 0.0418 mmpy, sedangkan material yang menggunakan material abrasif alumunium oxide memiliki nilai laju korosi sebesar 0.0457 mmpy. Dari pengujian laju korosi diketahui bahwa nilai semakin tinggi nilai daya lekat cat pada material maka material tersebut akan memiliki ketahanan korosi yang cukup baik. Hal ini dapat dilihat bahwa material yang di blasting menggunakan material abrasif steel grit memiliki nilai daya lekat tertinggi diantara material yang di blasting dengan material abrasif jenis lain. Hasil ini juga berbanding lurus dengan ketahanan korosi dari material tersebut dimana material yang di blasting menggunakan material abrasif steel grit memiliki nilai laju korosi yang terkecil.

\section{KESIMPULAN}

\section{A. Kesimpulan}

Setelah dilakukan analisa hasil pengujian, maka dapat diambil suatu kesimpulan dari penelitian yang dikerjakan . Berikut kesimpulannya :

1. Semakin tinggi nilai kekerasan partikel material abrasif yang digunakan untuk proses blasting, maka akan semakin tinggi nilai kekasaran permukaan yang diperoleh. Nilai kekasaran permukaan tertinggi diperoleh dari material yang di blasting menggunakan steel grit yaitu sebesar $84.71 \mu \mathrm{m}$.

2. Semakin tinggi nilai kekasaran permukaan akan meningkatkan nilai daya lekat cat dengan substrat. Hal ini ditunjukan dengan nilai daya lekat cat yang menggunakan steel grit sebagai material abrasif untuk blasting memiliki daya lekat sebesar 20.04 MPa untuk cat jenis epoxy dan 21.46 MPa untuk cat jenis zinc rich.

3. Di pengujian salt spray selama 72 jam nilai daya lekat tertinggi sebesar 14.15 MPa untuk cat jenis epoxy dan 15.04 MPa untuk cat jenis zinc rich. Di pengujian salt spray selama 1168 jam nilai daya lekat tertinggi sebesar 11.91 MPa untuk cat jenis epoxy dan 12.80 MPa untuk cat jenis zinc rich. Material yang memiliki daya lekat tertinggi dalam pengujian ini adalah material yang menggunakan steel grit sebagai material abrasif untuk blasting.

4. Ketahanan korosi suatu material juga dipengaruhi kekuatan daya lekat cat, semakin besar daya lekat cat suatu material, maka ketahanan korosi material tersebut 
akan semakin baik yang ditunjukan dengan nilai laju korosi pada material yang menggunakan material abrasif steel grit memiliki nilai laju korosi yang paling kecil diantara material yang di blasting menggunakan material abrasif lain nya yaitu 0.0374 mmpy untuk material yang di cat dengan epoxy dan 0.353 mmpy untuk untuk material yang di cat dengan zinc rich.

\section{B. Saran}

Untuk penelitian lebih lanjut sehingga dapat melengkapi penilitian ini penulis memberikan saran sebagai berikut:

1. Melanjutkan penelitian ini dengan melakukan analisa pengaruh ukuran mesh size material abrasif pada blasting terhadap kekuatan lekat cat dan ketahanan korosi pada lingkungan air laut,

2. Melakukan pengujian korosif lebih lanjut dan mencari produk korosi yang terbentuk.

\section{DAFTAR PUSTAKA}

[1] Holmberg, K. dan Matthews, A. 2010. "Coating Tribology Properties, Mechanisms, Techniques, and Aplications in surface Engineering Second Edition".The University of Sheffield: UK.

[2] Hudson, R. 1982. "Surface Preparation for Coating". The National Physical Labotary.

[3] ASTM D4541-02. 2002. "Standard Test Method for Pull-Off Strength of Coatings Using Portable Adhesion Testers”. Annual Book of ASTM Standards, Vol 15.06.

[4] ASTM B117-07. 2007. "Standard Practice for Operating Salt Spray (Fog) Apparatus". Annual Book of ASTM Standards, Vol 15.06.

[5] ASTM D4417-03. 2003. "Standard Test Methods for Field Measurement of Surface Profile of Blast Cleaned Steel”. Annual Book of ASTM Standards, Vol 06.01.

[6] ISO 8501. 2011. "Corrosion Protection of Steel Structures by Painting". International Organization for Standardization.

[7] SSPC: The Society for Protective Coatings. 2002. "SSPC-VIS 1 - Guide and Reference Photographs for Steel Surfaces Prepared by Dry Abrasive Blast Cleaning”. The Society for Protective Coatings.

[8] Norsok Standard M-501. 1994. "Surface Preparation and Protective Coating”. Norsok Standard.

[9] Vitosyto, J. 2012. "The Effects of Surface Roughness on Adhesion Strength of Coated Ash (Fraxinus excelsior L.) And Birch (Betula L.) Wood". Department of Wood Technology, Kaunas University of Technology

[10] Bondan T, S. 2009. "Pengaruh Temperatur Aplikasi Terhadap Karakteristik Die Coating 0.12 dan $0.14 \mathrm{~mm}$ pada Cetakan Piston Aluminium”. Jurnal Industri ITS , 8, 22-29. 